\title{
DIGITAL LEARNING IN FOREIGN LANGUAGE TEACHER TRAINING IN HIGHER EDUCATION: A CASE STUDY
}

\author{
Giovanna Carlon \\ Dr. University of Urbino, ITALY, giovanna.carloni@uniurb.it
}

\begin{abstract}
The Community of Inquiry framework provides a model to design and implement online and blended learning effectively from a socio-constructivist perspective which conceives learning as socially constructed (Garrison et al., 2000; Garrison and Arbaugh, 2007; Vaughan et al., 2013). The Community of Inquiry model includes teaching, social, and cognitive presence which need to be successfully implemented to foster effective online learning (Garrison et al., 2000; Garrison and Arbaugh, 2007; Vaughan et al., 2013). In this light, when higher education transitioned online due to the national lockdown in Italy, an instructor redesigned a graduate foreign language teacher training course, implemented at an Italian university, within the Community of Inquiry framework. As a result, students engaged in emergency remote learning (Bozkurt et al., 2020; Bozkurt and Sharma, 2020; Hodges et al., 2020) while experiencing practices targeted at fostering teaching, social, and cognitive presence in a time of crisis. In this perspective, a study was carried out to investigate students' perceptions of the effectiveness of the emergency remote education implemented in the course within the Community of Inquiry framework. To this purpose, after the end of the course, students filled in the Community of Inquiry Survey Instrument, suitable for investigating students' perceptions of the effectiveness of the teaching, social, and cognitive presence implemented in the course. Overall, findings show that students perceived as effectively implemented the three types of presence although social presence was the one that scored the lowest. The findings emerging from the study may be useful to other institutions planning to design and implement similar blended and/or fully online courses in higher education in the future.
\end{abstract}

Keywords: emergency remote teaching, digital learning, foreign language pedagogy, teacher training.

\section{EMERGENCY REMOTE TEACHING IN A FOREIGN LANGUAGE TEACHER TRAINING COURSE}

\subsection{Introduction}

The Covid-19 lockdown forced higher education to transition to emergency remote teaching (Bozkurt et al., 2020; Bozkurt and Sharma 2020; Hodges et al., 2020), also called emergency e-learning (Murphy, 2020, p. 492), worldwide in early March 2020. Pivoting courses online was a challenge for instructors and students who had to switch to new modes of teaching and learning almost overnight while facing a global health crisis. In this light, the present study aims to investigate students' perceptions of the effectiveness of the teaching, social, and cognitive presence, namely the core components of the Community of Inquiry (Col) framework (Garrison et al., 2000; Garrison and Arbaugh, 2007; Vaughan et al., 2013), implemented in a foreign language teacher trainer course transitioned online at an Italian university during the pandemic. 


\subsection{Designing Online Learning Environments}

The Community of Inquiry model, devised to design and implement distance learning successfully, features three core elements, namely teaching, social, and cognitive presence, which need to be integrated for effective online learning to occur (Garrison et al., 2000; Garrison and Arbaugh, 2007; Vaughan et al., 2013). The Col framework is based on a socio-constructivist view of learning (Garrison et al., 2000; Garrison and Arbaugh, 2007; Vaughan et al., 2013) which envisions knowledge as socially constructed (Vygostky, 1978; Lantolf, 2000).

In the Col model, teaching presence is operationalized through "[both] the design of the educational experience[,] [which] [...] includes the selection, organization, and primary presentation of course content, as well as the design and development of learning activities and assessment[,] [...] [and] facilitation" (Garrison et al., 2000, p. 89). In particular, teaching presence features three indicators. Instructional management, namely the first indicator, refers to the design and implementation of the curriculum, activities, and assessment (Garrison et al., 2000, p. 101). Building understanding, which is the second indicator, refers instead to the practices implemented to foster content knowledge acquisition (Garrison et al., 2000, p. 101), such as "creating an effective group consciousness for the purpose of sharing meaning, identifying areas of agreement and disagreement, and generally seeking to reach consensus and understanding" (Garrison et al., 2000, p. 101). Direct instruction, i.e. the third indicator, refers to the practices implemented to manage activities (from providing instructions to facilitating online discussions as well as providing summative and formative assessment) since it is "[t]he teacher's [...] responsibility [...] to facilitate reflection and discourse by presenting content, questions and proactively guiding and summarizing the discussion as well as confirming understanding through various means of assessment and feedback" (Garrison et al., 2000, pp. 101-102).

Social presence is defined as "the ability of participants in a community of inquiry to project themselves socially and emotionally, as 'real' people (i.e., their full personality), through the medium of communication being used" (Garrison et al., 2000, p. 89). Social presence features three indicators: the expression of emotion, i.e. an emotional response to the learning experience, which can be implemented through humor and self-disclosure; open communication, fulfilled through interactions showing mutual awareness, i.e. respect for peer-generated contributions, and recognition, i.e. acknowledgment of peer-generated contributions (Garrison et al., 2000, p. 100); and group cohesion, enhanced through strategies targeted at making students feel as members of a learning community, which is instrumental in fostering information sharing and collaborative critical thinking (Garrison et al., 2000, p. 101). In a community of enquiry where collaborative tasks aim to foster critical thinking (Garrison et al., 2000, p. 96), the implementation of relationship-building strategies suitable for promoting an emotionally safe place for students' interactions is of paramount importance. In this respect, instructors and students have to bear in mind that "in a true community of inquiry, the tone of the messages is questioning but engaging, expressive but responsive, skeptical but respectful, and challenging but supportive" (Garrison et al., 2000, p. 96).

Cognitive presence, deeply connected to critical thinking and metacognition, consists in "the extent to which the participants in any particular configuration of a community of inquiry are able to construct meaning through sustained communication" (Garrison et al., 2000, p. 89). Cognitive presence includes four indicators:

The first category of cognitive presence [...] is a state of dissonance or feeling of unease resulting from an experience. This category is described as that of a triggering event or communication. The second category $[\ldots]$ is that of exploration in a search for information, knowledge and alternatives that might help to make sense of the situation or problem. This category is described as that of searching for clarification and attempting to orient one's attention. The third category is integrating the information and knowledge into a coherent idea or concept. The description here is looking for insights and gaining some understanding of the acquired information and knowledge. The fourth category is the resolution of the issue or problem. This category is described as an application of an idea or hypothesis. The success of the application and whether the idea is confirmed will determine whether the process of inquiry continues. (Garrison et al., 2000, pp. 98-99)

Students are more likely to engage in collaborative critical thinking when social presence has been developed successfully in online learning environments (Garrison et al., 2000; Garrison and Arbaugh, 2007; Vaughan et al., 2013). In this light, the Col design principles provided below highlight the key role played by the integration of the teaching, social, and cognitive presence in online collaborative learning:

1. Plan for the creation of open communication and trust

2. Plan for critical reflection and discourse 

3. Establish community and cohesion
4. Establish inquiry dynamics (purposeful inquiry)
5. Sustain respect and responsibility
6. Sustain inquiry that moves to resolution
7. Ensure assessment is congruent with intended processes and outcomes. (Garrison, 2017, p. 112)

The Community of Inquiry model has been implemented in online synchronous and asynchronous learning successfully (Zydney, Denoyelles, and Seo, 2012; Lambert and Fisher, 2013; Bozkurt, 2019; Archer-Kuhn et al., 2020; Junus et al., 2019; Borup et al., 2020; Suppiah et al., 2020; Zhang, 2020). In particular, positive findings have emerged from the investigation of the implementation of the teaching, social, and cognitive presence (Akyol and Garrison, 2008; Oriogun, 2009; Garrison et al., 2010; Gutiérrez-Santiuste et al., 2015); Kozan, 2016; Yang, 2016; Tirado-Morueta et al., 2016; Richardson et al., 2017; Rolima et al., 2019). The Community of Inquiry model has also been successfully implemented in online teacher training courses. In this respect, studies have highlighted the positive impact that social presence (Cullen et al., 2013; Komnimou, 2017; Jaber et al., 2018; Jackson and Jones, 2019; Theelen et al., 2020), cognitive presence (Jones and Ryan, 2014; Dooly and Sadler, 2020), and teaching presence (Biasutti and EL-Deghaidy, 2014; Evans et al., 2017) have on online learning.

The Col model was adopted to design emergency remote teaching in a foreign language teacher training course during the Covid-19 lockdown. In this respect, there is no research focusing on students' perceptions of the teaching, social, and cognitive presence, collected through the Community of Inquiry Survey Instrument ${ }^{1}$, implemented in emergency remote teacher training during the Covid-19 lockdown. The present study thus aims to investigate this pedagogical aspect using the Community of Inquiry Survey Instrument. The analysis conducted is likely to provide information useful to design flexible courses in post-pandemic higher education, where content-specific knowledge development needs to be integrated with pedagogy of care catering to students' emotional and psychological needs (Bozkurt et al., 2020).

\subsection{Emergency Remote Teaching in a Foreign Language Teacher Training Course}

The Community of Inquiry model (Garrison et al., 2000; Garrison and Arbaugh, 2007; Vaughan et al., 2013) was adopted to design emergency remote teaching (Bozkurt et al., 2020; Bozkurt and Sharma, 2020; Hodges et al., 2020) for a graduate foreign language teacher training course, focusing on CLIL (Content and Language Integrated Learning) (Coyle et al., 2010), implemented at an Italian university during the Covid-19 lockdown. The Col model was operationalized through a design for learning approach: "learning cannot be designed. [...] [It] can be designed for" (Goodyear, 2015, p. 41); the design for learning approach highlights the necessity to foster active learning in online learning environments (Rapanta et al., 2020). In this light, when transitioning the course online due to the pandemic, the instructor redesigned the course in keeping with the socio-constructivist theoretical tenets of the Col framework (Garrison et al., 2000; Garrison and Arbaugh, 2007; Vaughan et al., 2013; Selwyn, 2016). In this respect, collaborative learning focusing on the development of students' professional skills through inquiry was implemented; while pivoting the course online, a switch from content to skills development thus occurred in keeping with digital pedagogy (Trammell and LaForge, 2017; Martin et al.,, 2019). As a result, more focus on students' critical thinking enhanced by means of collaborative knowledge construction and reflection was fostered; students' responsibility for their own learning, an essential component of online learning (Vaughan et al., 2013), was thereby also promoted.

In the pivoted course, emergency remote teaching consisted in two-hour long synchronous classes, held in Blackboard Collaborate web conferencing, and out-of-class digitally-enhanced activities. As part of cognitive presence, the instructor provided students with weekly and daily learning outcomes, which was suitable for promoting students' metacognition and self-regulation. Live classes started with a digitally-enhanced brainstorming activity, targeted at activating students' prior knowledge (Miller, 2014), followed by short instructor-delivered lectures (Bates, 2016; Darby and Lang, 2019); after listening to the lectures, students engaged in technology-enhanced tasks aimed at promoting critical thinking and knowledge development. Students thus often switched activities as online pedagogy requires (Bates, 2016; Darby and Lang, 2019). Digitally-enhanced ice breaker activities targeted at fostering students' social presence were implemented during emergency remote teaching in keeping with a pedagogy of care (Motta and Bennett, 2018; Bozkurt et al., 2020). As out-of-class activities, using open educational resources, students created digitally-enhanced

\footnotetext{
${ }^{1}$ https://coi.athabascau.ca/coi-model/coi-survey.
} 
CLIL teaching activities which they shared with the class in a forum; feedback from peers and the instructor was thus enhanced. Summative assessment was tailored to the online learning experience (Conrad and Openo, 2018). In particular, as part of summative assessment, students engaged in digitally-enhanced collaborative CLIL teaching materials design in class and out of class; to this purpose, from an open pedagogy perspective, students used digital open educational resources to devise CLIL teaching units in English. Furthermore, within the Community of Inquiry theoretical framework, the instructor provided students with timely formative assessment in oral, written, and audio modes both in and out of class consistently (Garrison et al., 2000; Garrison and Arbaugh, 2007; Vaughan et al., 2013; Conrad and Openo, 2018). Providing students with timely formative assessment is likely to affect students' learning successfully in online learning environments while at the same time promoting social presence (Vaughan et al., 2013; Conrad and Openo, 2018).

\section{A CASE STUDY}

\subsection{Research Questions}

The study addressed the following research question: how effective did students perceive the teaching, social, and cognitive presence implemented in the emergency remote course devised within the Community of Inquiry framework?

\subsection{The Participants}

The cohort for the present study consisted of nineteen Italian students attending a foreign language teacher training course implemented at graduate level at an Italian university.

\subsection{The Method}

Descriptive research was carried out using the data collected through the Community of Inquiry Survey Instrument, which is a structured questionnaire made available as an openly licensed resource. The Community of Inquiry Survey Instrument, designed to investigate students' perceptions of the teaching, social, and cognitive presence implemented in online learning environments, has been validated (Arbaugh et al., 2008; Swan et al., 2008; Garrison, 2017; Garrison, 2018; Wei et al., 2020). The Community of Inquiry Survey Instrument uses a 5-point Likert scale with two bi-polar values (strongly disagree and strongly agree) at each end. In the present study, the Community of Inquiry Survey Instrument was administered online after the end of the course to collect students' perceptions of the teaching, social, and cognitive presence implemented during emergency remote teaching.

\subsection{Results and Analysis}

In this section, the data analyzed were gathered through the Community of Inquiry Survey Instrument that students filled in online after the end of the course. The data examined are not the result of a controlled experiment. It is also important to mention that the number of students involved in the study is too small to reach conclusive results although some interesting phenomena detected can be useful for further investigation.

As previously mentioned, teaching presence includes design and organization, facilitation, and direct instruction. In terms of design and organization, all students claimed $(89,5 \%$ strongly agreed and $10,5 \%$, namely two students, agreed) that the instructor communicated the course topics clearly. Likewise, students either strongly agreed $(78,9 \%)$ or agreed $(21,1 \%)$ that the instructor communicated clearly the course goals; to the same extent, students held that the instructor provided clear instructions on how to participate in course learning tasks. All students thought (94,7\% strongly agreed and one student, namely 5,3\%, agreed) that the instructor communicated important deadlines and time frames for learning activities clearly. Data suggest that the instructor managed design and organization rather successfully.

In terms of facilitation, over half of the students strongly agreed $(57,9 \%)$ and the rest agreed $(42,1 \%)$ that the instructor helped students to identify areas of agreement and disagreement in the course topics, which promoted students' learning effectively. Most students strongly agreed $(78,9 \%)$ and the others agreed $(21,1 \%)$ that the instructor scaffolded learners' comprehension of the course topics in a way that helped them to understand subject-specific content clearly, which suggests that the strategies implemented succeeded in enhancing students' learning processes successfully. Likewise, students highly appreciated $(84,2 \%$ strongly agreed and $15,8 \%$ agreed) the strategies the instructor used to keep them engaged and active in effective dialogical interactions. Just to a slightly lower extent $(73,7 \%$ strongly agreed and $26,3 \%$ agreed), students perceived the instructor's help as instrumental in keeping the course participants on task, 
thereby fostering active learning. To a slightly higher degree, all students found ( $84,2 \%$ strongly agreed and $15,8 \%$ agreed) the instructor's encouragement to explore new concepts in the course effective. Furthermore, students valued rather highly $(63,2 \%$ strongly agreed and $36,8 \%$ agreed) the strategies implemented to develop a sense of community in the online learning environment. In this respect, more pair and group work could have been implemented in breakout rooms right from the start to strengthen students' sense of belonging to a community in a time of crisis even further.

In terms of direct instruction, all students held $(63,2 \%$ strongly agreed and $36,8 \%$ agreed) that the instructor helped to focus discussion on key issues in a way that helped them to learn. To a slightly higher degree (73,7\% strongly agreed and $26,3 \%$ agreed), students claimed that the instructor provided feedback that helped them to understand their strengths and weaknesses in relation to the course learning outcomes, which suggests that students' metacognition was fostered rather successfully. To the same degree $(73,7 \%$ strongly agreed and $26,3 \%$ agreed), students held that the instructor provided feedback in a timely fashion, which entails that students' perceived formative assessment as catering to their needs effectively.

As previously mentioned, social presence includes affective expression, open communication, and group cohesion. In terms of affective expression, about half of the students strongly agreed $(52,6 \%)$ and the rest agreed $(47,4 \%)$ that getting to know each other gave them a sense of belonging in the online learning environment. Almost to the same extent $(52,6 \%$ strongly agreed and $42,1 \%$ agreed while one student, namely $5,3 \%$, was neutral), students claimed that they succeeded in forming distinct impressions of their peers. In this respect, the instructor could have implemented more ice breaker activities to increase informal interaction among students further, thereby helping learners to get to know each other more thoroughly on a personal level especially in a context where social distancing forced them to live consistently isolated from their peers. To a much lower extent, students perceived (10,5\% strongly agreed and $47,4 \%$ agreed while 8 students, namely $42,1 \%$, were neutral) online communication as an excellent medium for social interaction. These findings suggest that online communication could have been promoted further especially using digital tools, available as open educational resources, suitable for enhancing engaging and highly interactive formal and informal online communication, instrumental in increasing students' social presence.

In terms of open communication, most students (57,9\% strongly agreed and $26,3 \%$ agreed) felt comfortable interacting through the online medium while only 3 students $(15,8 \%)$ were neutral. Almost to the same degree (52,5\% strongly agreed and $36,8 \%$ agreed while 2 students, namely $10,5 \%$, were neutral), students felt comfortable participating in the course discussions. Findings suggest that the instructor could have adopted further strategies to make all students feel comfortable to a very high degree while communicating online. To a slightly higher extent, students felt comfortable $(73,7 \%$ strongly agreed and $21,1 \%$ agreed while one student, namely $5,3 \%$, was neutral) interacting with their peers.

In terms of group cohesion, most students (52,6\% strongly agreed and $21,1 \%$ agreed) felt comfortable disagreeing with their peers while keeping a relationship based on trust; 5 students, namely $26,3 \%$, were instead neutral. These findings suggest that the instructor could have used more strategies in order to make all students feel highly comfortable to express disagreement. For example, through modelling, the instructor could have shown students how to disagree respectfully and how to use this practice to foster deep learning; to this purpose, students should have been pre-trained to develop effective debating skills before engaging in online subject-specific exchanges. Significantly, all students felt $(52,6 \%$ strongly agreed and $47,4 \%$ agreed) that their point of view was acknowledged by their peers, which suggests that learners were able to respect and value the other participants' ideas and feelings to a rather good degree. Most students (63,2\% strongly agreed and $26,3 \%$ agreed) held that online discussions helped them to develop a sense of collaboration while 2 students, namely 10,5\%, were neutral. In this respect, the instructor could have highlighted the pedagogical value of online collaboration in terms of relationship and knowledge building right from the start.

As previously mentioned, cognitive presence includes triggering event, exploration, integration, and resolution. In terms of triggering event, most students claimed (57,9\% strongly agreed and $36,8 \%$ agreed while one student was neutral) that the problems provided increased their interest in the course topics, which suggests that most students perceived critical thinking as effective in terms of content-specific knowledge development. Furthermore, all students held (73,7\% strongly agreed and $26,3 \%$ agreed) that course activities triggered their curiosity; even to a slightly higher degree $(84,2 \%$ strongly agreed and $15,8 \%$ agreed), students felt motivated to investigate subject-specific questions. Students thus seem to have experienced critical thinking, which is pivotal in online learning, to a rather high degree.

In terms of exploration, all students felt that they had used a wide range of resources to investigate the problems posed in the course to a rather good degree (52,6\% strongly agreed and 47,45 agreed); to the 
same extent, students found that brainstorming and finding relevant information helped them to tackle subject-specific questions effectively. To a slightly lower degree $(63,2 \%$ strongly agreed and $31,6 \%$ agreed while one student was neutral), students found that online discussions were valuable in helping them to appreciate different perspectives. Students thus seem to have experienced critical evaluation of multimodal resources and negotiation of multiple perspectives as effective learning practices.

In terms of integration, all students (57,9\% strongly agreed and $42,1 \%$ agreed) felt that combining new information helped them to answer the questions raised during course activities. Almost to the same extent (68,4\% strongly agreed and $31,6 \%$ agreed), all students thought that learning activities helped them to formulate explanations and find solutions. All students also felt to a rather high degree $(73,7 \%$ strongly agreed and $26,3 \%$ agreed) that reflection on course content and discussions helped them to understand the key concepts investigated in the course. In this respect, it is noteworthy that students engaged in weekly reflection, which was probably instrumental in promoting metacognition extensively.

In terms of resolution, all students $(68,4 \%$ strongly agreed and $31,6 \%$ agreed) claimed that they can describe ways to test and apply the knowledge created in the course and that they have developed solutions to course problems that can be implemented in real contexts. Furthermore, to a very high degree $(84,2 \%$ strongly agreed and $15,8 \%$ agreed), students felt that they can apply in their professional fields the knowledge developed. In this respect, the digitally-enhanced activities implemented and the collaborative user-generated artefacts devised were probably instrumental in helping students to accomplish the skills development course outcomes.

Overall, the teaching, social, and cognitive presence seem to have been implemented to a rather high degree in the course during emergency remote teaching. However, comparing the three types of presence, social presence seems to have scored the lowest although the findings are overall positive. The results thus seem to suggest that when transitioning the course online, the instructor probably ended up focusing more on content and skills development, overlooking to a certain extent the necessity to foster social presence. This was probably due to the instructor's fear of not being able to help students to accomplish successfully the course learning outcomes, previously devised for face-to-face instruction, during emergency remote teaching.

\section{CONCLUSION}

Findings show that students perceived as rather effective the teaching, social, and cognitive presence implemented in the emergency remote course. Overall, the instructor should have focused more on developing social presence, also instrumental in fostering a pedagogy of care in a time of crisis. The results of the present study may be especially beneficial to design flexible courses, such as fully online and/or blended courses, for the 'new normal' of post-pandemic higher education.

\section{REFERENCE LIST}

Akyol, Z., \& Garrison, D.R. (2008). The development of a community of inquiry over time in an online course: Understanding the progression and integration of social, cognitive and teaching presence. Journal of Asynchronous Learning Network, 12 (3), 3-23. https://doi.org/10.24059/olj.v12i3.66.

Arbaugh, J.B., Cleveland-Innes, M., Diaz, S.R., Garrison, D.R., Ice, P., Richardson, \& Swan, K.P. (2008). Developing a community of inquiry instrument: Testing a measure of the Community of Inquiry framework using a multi-institutional sample. The Internet and Higher Education, 11 (3-4), 133-136.

Archer-Kuhn, B., Lee, Y., Finnessey, S., \& Liu, J. (2020). Inquiry-Based learning as a facilitator to student engagement in undergraduate and graduate social work programs. Teaching and Learning Inquiry, 8 (1), 187-207.

Bates, T. (2016). The 10 Fundamentals of Teaching Online for Faculty and Instructors. Contact North. https://teachonline.ca/sites/default/files/pdfs/the_10_fundamentals_of_teaching_online_for_faculty_an d_instructors_-_september_2016.pdf.

Biasutti, M., \& EL-Deghaidy, H. (2014). Interdisciplinary Project-based Learning: An Online Wiki Experience in Teacher Education. Technology, Pedagogy and Education, 24 (3), 339-355. doi:10.1080/1475939X.2014.899510. 
Blackboard Collaborate. https://www.blackboard.com/teaching-learning/collaboration-webconferencing/blackboard-collaborate.

Borup, J., Graham, C.R., West, R.E., Archambault, L., \& Spring, K.J. (2020). Academic communities of engagement: An expansive lens for examining support structures in blended and online learning. Educational Technology Research Development, 68, 807-832. https://doi.org/10.1007/s11423-02009744-X.

Bozkurt, A. (2019). Intellectual roots of distance education: a progressive knowledge domain analysis. Distance Education, 40 (4), 497-514.

Bozkurt, A., Jung, I., Xiao, J., Vladimirschi, V., Schuwer, R., Egorov, G., Lambert, S.R., Al-Freih, M., Pete, J., Olcott, D., Rodes, V., Aranciaga, I., Bali, M., Alvarez, A.V., Roberts, J., Pazurek, A., Raffaghelli, J.E., Panagiotou, N., de Coëtlogon, P., Shahadu, S., Brown, M., Asino, T.I., Tumwesige, J., Ramírez Reyes, T., Barrios Ipenza, E., Ossiannilsson, E., Bond, M., Belhamel, K., Irvine, V., Sharma, R.C., Adam, T., Janssen, B., Sklyarova, T., Olcott, N., Ambrosino, A., Lazou, C., Mocquet, B., Mano, M., \& Paskevicius, M. (2020). A global outlook to the interruption of education due to COVID-19 Pandemic: Navigating in a time of uncertainty and crisis. Asian Journal of Distance Education, 15 (1), 1-126.

Bozkurt, A., \& Sharma, R.C. (2020). Emergency remote teaching in a time of global crisis due to CoronaVirus pandemic. Asian Journal of Distance Education, 15 (1), i-vi.

Community of Inquiry Survey Instrument. https://coi.athabascau.ca/coi-model/coi-survey.

Conrad, D., \& Openo, J. (2018). Assessment Strategies for Online Learning Engagement and Authenticity. Edmonton, AB: Athabasca University Press.

Coyle, D., Hood, P., \& Marsh, D. (2010). CLIL Content and Language Integrated Learning. Cambridge: Cambridge University Press.

Cullen, R., Kullman, J., \& Wild, C. (2013). Online Collaborative Learning on an ESL Teacher Education Programme. ELT Journal, 67 (4), 425-434. doi:10.1093/elt/cct032.

Darby, F., \& Lang, J.M. (2019). Small Teaching Online: Applying Learning Science in Online Classes. San Francisco, CA: Jossey-Bass Wiley.

Dooly, M., \& Sadler, R. (2020). 'If You Don't Improve, What's the Point?' Investigating the Impact of a 'Flipped' Online Exchange in Teacher Education. ReCALL, 32 (1), 4-24. doi:10.1017/S0958344019000107.

Evens, M., Larmuseau, C.H., Dewaele, K., Craesbeek, L.V., Elen, J., \& Depaepe, F. (2017). The Effects of a Systematically Designed Online Learning Environment on Pre-service Teachers' Professional Knowledge. Journal of Digital Learning in Teacher Education, 33 (3), 103-113. doi:10.1080/21532974.2017.1314779.

Garrison, D.R. (2017). E-Learning in the 21st Century: A Community of Inquiry Framework for Research and Practice (3rd edition). London: Routledge.

Garrison, D.R. (2018). Validity of Col. http://www.thecommunityofinquiry.org/editorial15.

Garrison, D.R., Anderson, T., \& Archer, W. (2000). Critical inquiry in a text-based environment: Computer conferencing in higher education. The Internet and Higher Education, 2 (2-3), 87-105. https://doi.org/10.1016/s1096.

Garrison, D.R., \& Arbaugh, J.B. (2007). Researching the community of inquiry framework: Review, issues, and future directions. The Internet and Higher Education, 10 (3), 157-172.

Garrison, D.R., Cleveland-Innes, M., \& Fung T.S. (2010). Exploring causal relationships among teaching, cognitive and social presence: Student perceptions of the community of inquiry framework. Internet and Higher Education, 13 (1-2), 31-36. https://doi.org/10.1016/j.iheduc.2009.10.002.

Goodyear, P. (2015). Teaching as design. Herdsa Review of Higher Education, 2 (2), 27-50. https://doi. org/10.1111/hea.12037_26.

Gutiérrez-Santiuste, E., Rodríguez-Sabiote, C., \& Gallego-Arrufat, M.J. (2015). Cognitive presence through social and teaching presence in communities of inquiry: A correlational-predictive study. Australasian Journal of Educational Technology, 31 (3), 349-362. 
Hodges, C., Moore, S., Lockee, B., Trust, T., \& Bond, A. (2020). The Difference between Emergency Remote Teaching and Online Learning. Educause Review, March 27. https://er.educause.edu/articles/2020/3/the-difference-between-emergency-remote-teaching-andonline-learning.

Jaber, L.Z., Dini, V., Hammer, D., \& Danahy, E. (2018). Targeting Disciplinary Practices in an Online Learning Environment. Science Education, 102 (4), 668-692. doi:10.1002/sce.21340.

Jackson, B.L., \& Jones, M. (2019). Where the Rubber Meets the Road: Exploring the Perceptions of Inservice Teachers in a Virtual Field Experience. Journal of Research on Technology in Education, 51 (1), 7-26. doi:10.1080/15391523.2018.1530622.

Jones, M., \& Ryan, J. (2014). Learning in the Practicum: Engaging Pre-service Teachers in Reflective Practice in the Online Space. Asia-Pacific Journal of Teacher Education, 42 (2), 132-146. doi:10.1080/1359866X.2014.892058.

Junus, K., Suhartanto, H., R-Suradijono, S.H., Santosa, H.B., \& Sadita, L. (2019). The Community of Inquiry model training using the cognitive apprenticeship approach to improve students' learning strategy in the asynchronous discussion forum. Journal of Educators Online, 16 (1). https://www.thejeo.com/archive/2019_16_1/janus_suhartanto_rsuradijono_santoso_sadita.

Komninou, I. (2017). A Case Study of the Implementation of Social Models of Teaching in E-learning: 'The Social Networks in Education', Online Course of the Inter-orthodox Centre of the Church of Greece. TechTrends, 62 (2), 146-151. doi:10.1007/s11528-017-0247-4.

Kozan, K. (2016). A comparative structural equation modeling investigation of the relationships among teaching, cognitive and social presence. Online Learning, 20 (3), 210-227.

Lambert, J.L., \& Fisher, J.L. (2013). Community of Inquiry framework: Establishing community in an online course. Journal of Interactive Online Learning, 12 (1), 1-16. http://www.ncolr.org/jiol/issues/pdf/12.1.1.pdf.

Lantolf, J. (2000). Introducing Sociocultural Theory. In J. Lantolf (ed.), Sociocultural Theory and Second Language Learning. Oxford: Oxford University Press. 1-26.

Martin, F., Ritzhaupt, A., Kumar, S., \& Budhrani, K. (2019). Award-winning faculty online teaching practices: Course design, assessment and evaluation, and facilitation. The Internet and Higher Education, 42, 34-43. https://doi.org/10.1016/j.ineduc.2019.04.001.

Miller, M.D. (2014). Minds Online. Teaching Effectively with Technology. Harvard: Harvard University Press.

Motta, S.C., \& Bennett, A. (2018). Pedagogies of care, care-full epistemological practice and 'other' caring subjectivities in enabling education. Teaching in Higher Education, 23 (5), 631-646. DOI: $10.1080 / 13562517.2018 .1465911$.

Murphy, M.P.A. (2020). COVID-19 and Emergency eLearning: Consequences of the Securitization of Higher Education for Post-pandemic Pedagogy. Contemporary Security Policy, 41 (3), 492-505. doi:10.1080/13523260.2020.1761749.

Oriogun, P.K. (2009). Detecting aspects of critical thinking by cleaning online message transcript through code-recode. The American Journal of Distance Education, 23 (1), 34-50. https://doi.org/10.1080/08923640802661694.

Rapanta, C., Botturi, L., Goodyear, P., Guàrdia, L., \& Koole, M. (2020). Online University Teaching During and After the Covid-19 Crisis: Refocusing Teacher Presence and Learning Activity. Postdigit Sci Educ. https://doi.org/10.1007/s42438-020-00155-y.

Richardson, J.C., Maeda, Y., Lv, J., \& Caskurlu, S. (2017). Social presence in relation to students' satisfaction and learning in the online environment: A meta-analysis. Computers in Human Behavior, 71, 402-417. https://doi.org/10.1016/j.chb.2017.02.001.

Rolima, V., Ferreiraa, R., Linsa, R.D., \& Găsević, D. (2019). Network-based analytic approach to uncovering the relationship between social and cognitive presences in Communities of Inquiry. Internet and Higher Education, 42, 53-65.

Selwyn, N. (2016). Education and Technology. Key Issues and Debates. London: Bloomsbury.

Suppiah, S., Wah, L.K., Lajium, D.A., \& Swanto, S. (2020). Exploring a collaborative and dialogue-based 
reflective approach in an e-learning environment via the Community of Inquiry (Col) Framework. CALL-EJ, 20 (3), 117-139.

Swan, K., Shea, P., Richardson, J., Ice, P., Garrison, D.R., Cleveland-Innes, M., \& Arbaugh, J.B. (2008). Validating a measurement tool of presence in online communities of inquiry. E-Mentor, 2 (24), $1-12$.

Theelen, H., Willems, M.C., van den Beemt, A., Conjin, R., \& den Brok P. (2020). Virtual Internships in Blended Environments to Prepare Preservice Teachers for the Professional Teaching Context. British Journal of Educational Technology, 51 (1), 194-210. doi:10.1111/bjet.12760.

Tirado-Morueta, R., Maraver-López, P., Hernando-Gómez, Á., \& Harris, V.W. (2016). Exploring social and cognitive presences in communities of inquiry to perform higher cognitive tasks. Internet and Higher Education, 31, 122-131. https://doi.org/10.1016/j.iheduc.2016.07.00.

Trammell, B.A., \& LaForge, C. (2017). Common challenges for instructors in large online courses: Strategies to mitigate student and instructor frustration. Journal of Educators Online, 14 (1), 1-10.

Vaughan, N.D., Cleveland-Innes, M., \& Garrison, D.R. (2013). Teaching in Blended Learning Environments: Creating and Sustaining Communities of Inquiry. Edmonton, AB: Athabasca University Press.

Vygotsky, L.S. (1978). Mind in Society: The Development of Higher Psychological Processes. Cambridge, MA: Harvard University Press.

Wei, L., Hu, Y., Zuo, M., \& Luo, H. (2020). Extending the COI Framework to K-12 Education: Development and Validation of a Learning Experience Questionnaire. In S. Cheung, R. Li, K. Phusavat, N. Paoprasert, \& L. Kwok (eds.), Blended Learning. Education in a Smart Learning Environment. ICBL 2020. Lecture Notes in Computer Science, 12218. Cham: Springer. https://doi.org/10.1007/978-3-030-51968-1_26.

Yang, J.C., Quadir, B., Chen, N-S., \& Miao, Q. (2016). Effects of online presence on learning performance in a blog-based online course. Internet and Higher Education, 30, 11-20.

Zhang, R. (2020). Exploring blended learning experiences through the community of inquiry framework. Language Learning \& Technology, 24 (1), 38-53.

Zydney, J.M., deNoyelles, A., \& Seo, K.K. (2012). Creating a community of inquiry in online environments: An exploratory study on the effect of a protocol on interactions within asynchronous discussions. Computers and Education, 58 (1), 77-87. https://doi.org/10.1016/j.compedu.2011.07.009. 